African Journal of Biomedical Research, Vol. 10 (2007); 19 - 24

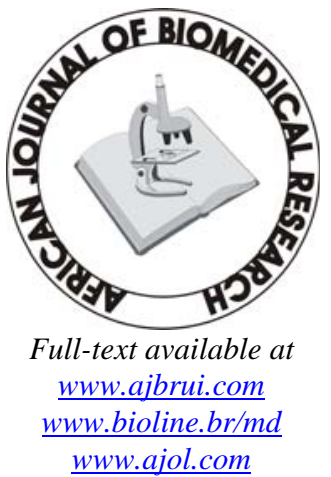

Received:

August, 2006

Accepted

December, 2006

Published

January, 2007
Full length Research Article

\section{Trichomoniasis in Special Treatment Clinic Patients in Ibadan, Nigeria}

\author{
O.A.Akinloye ${ }^{1}$, D.O. Ogbolu ${ }^{2}$, F.O. Kolade ${ }^{2}$, and \\ O.A.Terry Alli ${ }^{1,3}$ \\ 1 Department of Biomedical Sciences, College of Health Sciences, \\ Ladoke Akintola University of Technology, Osogbo, Nigeria, \\ 2 Department of Medical Microbiology, University College Hospital, \\ Ibadan, Nigeria, \\ 3 Department of Pathology and Microbiology, Medical School, \\ University of Bristol, Bristol, UK BS8 1TD.
}

\section{ABSTRACT}

Among 504 out-patients (males and females) suffering from various forms of sexually transmitted diseases at special treatment clinic in University College Hospital, Ibadan, 48 (9.5\%) of them were found to have Trichomonas viginalis. Trichomoniasis was found to be more prevalent in women (12.5\% of 280), thirteen (5.8\%) out of the 224 males had trichomoniasis with a high prevalence in the age bracket of $11-30$ years in both sexes. Large percentage of single women and men investigated (53\% and $26 \%$ respectively - $79 \%$ in all based on isolates) had trichomoniasis. It was discovered that $68.4 \%$ of patients infected with trichomoniasis had discharge (vaginal and urethral), 42.1\% had pain on passing urine while $10.5 \%$ had irritation on passing urine, and also $10.5 \%$ had increase frequency. Twenty-two (42\%) of 48 patients with $T$. vaginalis were diagnosed by microscopy of direct wet mount preparation, all the $48(100 \%)$ positive cases were diagnosed by culture. The two media (Trichomonas medium 2 (Oxoid) and NBGS supported the growth of $T$. vaginalis and they failed to show superiority over each other.

(Afr. J. Biomed. Res. 10: 19 - 24, January 2007)

Keywords: trichomoniasis, Trichomonas vaginalis, Prevalence, Sexually transmitted infection

*Address for Correspondence: e-mail: alliot@hotmail.com 


\section{INTRODUCTION}

Trichomonas vaginalis is an aetiological agent of trichomoniasis. Trichomoniasis is a sexually transmitted infection in humans with clinical conditions characterized by vaginal discharge, pruritus, and irritation in symptomatic women. Other clinical manifestations of this infection may include dysuria and lower abdominal pain. About $50 \%$ of the women with the infection developed no symptoms. The infection in majority of the males is asymptomatic and it has been suggested to be very important in nongonococcal and non-chlamydial urethritis (Krieger et al., 1993). Study has shown that men with symptomatic Trichomonas urethritis were found to have increased HIV concentrations in seminal plasma compared to HIV infected men without urethritis (Hobbs et al., 1999). Moreover, the acquisition of Human Immunodeficiency Virus has been associated with trichomoniasis in several studies conducted in Africa (Laga et al., 1993, Buve et al., 2001), meaning the organism needs to be taken seriously. Although trichomoniasis has been considered to be a minor sexually transmitted disease with few complications, infection with $T$. vaginalis infection has been shown to be responsible for preterm delivery in several studies (Cotch et al., 1997, Hardy et al., 1984). Acquisition of the organism by neonates during passage through the infected birth canal is possible. It has been estimated that 2 to $17 \%$ of female babies contracted $T$. vaginalis by direct vulvovaginal contamination (Laga et al., 1993). Studies have also shown $T$. vaginalis as a cause of neonatal pneumonia (Hienstra, 1984, Meri et al., 2000). From epidemiological point of view, $T$. vaginalis infection is associated with other sexually transmitted disease especially gonorrhoea. As a result of this, trichomoniasis is a marker of high risk sexual behaviour. Furthermore, recent work has linked $T$. vaginalis infection to invasive cervical cancer in 48 patients as demonstrated by the presence of antibodies to this organism (Sayed el-Ahl et al., 2002). Taken together all these information, there is need to give priority to this sexually transmitted parasitic infection. In order for any intervention to take place, the epidemiology of this organism needs to be studied since it is not a reportable disease.

Epidemiologically, T. vaginalis infections occur world-wide in both urban and rural settings. In the 1970's the World Health Organisation estimated an annual world incidence of 180 million cases; however, this infection is not notifiable, and any data on prevalence are therefore highly unreliable (Kampmeier, 1978). The World Health Organisation estimation put trichomoniasis as half of all curable infections worldwide (Cates, 1999). The incidence of trichomoniasis differs depending on the population examined. Studies on prevalence of $T$. vaginalis infection in Africa populations were estimated to be between 11 and 25\% (Leroy et al., 1995, Laga et al., 1993, Klouman et al., 1997). Laga et al reported an incidence of 38\% among HIV infected women (Laga et al., 1993). No data available on the prevalence of $T$. vaginalis among the patients attending Special Treatment Clinic (STC) at University College Hospital (UCH), Ibadan, Nigeria. It was in view of this, that the study was conducted to determine the prevalence of $T$. vaginalis infection in patients attending STC, UCH, Ibadan, Nigeria.

\section{MATERIALS AND METHODS}

A total of 504 out-patients attending the STC of $\mathrm{UCH}$ in Ibadan for period of 9 months were selected for possible participation in the screening study for trichomoniasis. The STC serves as a referral centre for sexual transmitted infections for the people living in Ibadan and its environs with estimated population of about 3 million. Each of these patients was questioned as to previous genitourinary symptoms; the previous antimicrobial drugs used before attending the clinic were also noted (clinical history). Urethral specimens were collected from all the 224 male patients used for the study using sterile cotton-wool swab. Urethral discharge was collected directly with a sterile bacteriological loop from those patients that had obvious urethral discharge, vaginal exudates was 
collected from the posterior fornix of 280 female patients with sterile cotton-wool swab. The 504 patients (males and females) were asked to produce urine specimens.

\section{Laboratory methods}

Wet preparations of the urethral swabs and the vaginal exudates were made using a drop of normal saline on microscope slide ( $22 \times 22 \mathrm{~mm})$ covered with cover slip and immediately examined under the microscope using the $\mathrm{x} 10$ and $x 40$ objectives. Each urine specimen was thoroughly mixed and $15 \mathrm{ml}$ alight was centrifuged at 3,000 $\mathrm{x} g$ for $10 \mathrm{~min}$ using electric bench centrifuge. The supernatant were discarded and one drop of the sediment was placed on a 22 x 22mm glass slide and covered with a cover glass. The preparation was examined for the presence of $T$. vaginalis under the microscope using the $\mathrm{x} 10$ and $\mathrm{x} 40$ objectives. T. vaginalis was identified with its characteristics morphology and darting motility.

Many media are available for the cultural diagnosis of trichomoniasis but commercially available Trichomonas medium 2 (Oxoid, UK) and Nutrient broth glucose serum (NBGS) medium (Adebayo, 1986) were used for this study. Culture media were inoculated directly with specimens taken from the same sites as those for microscopy. The inoculated media were incubated at $37^{\circ} \mathrm{C}$ for $48 \mathrm{~h}$ and examined microscopically for trichomonads, incubation was continued and cultures media examined daily for up to one week for negative cultures before being discarded.

\section{RESULTS}

The data in Table 1 shows that 48 (9.5\%) out of 504 patients attending STC, University College Hospital had trichomoniasis using the cultural method (Trichomonas medium 2) for screening. The cultural method of diagnosis was our "gold standard." Using this method, we found that the use of NBGS gave $100 \%$ sensitivity and 100\% specificity. The microscopical method which was based on wet preparation mount was found to be $42.1 \%$ sensitivity and $95 \%$ specificity compared to our gold standard. The prevalence of trichomoniasis in the population investigated was found to be $9.5 \%$. Thirty-five (12.5\%) out of 284 women and 13 (5.8\%) out of 220 men had trichomoniasis as demonstrated by cultural isolation of $T$. vaginalis. The breakdown of diagnosis of trichomonads infection using different samples is shown on table 2. The most striking finding of the study was the low level of detection of $T$. vaginalis in urine samples (3.5\% by culture) as opposed to high level of detection from vaginal/urethral swab ( $9.5 \%$ by culture). The level of detection of $T$. vaginalis was even worse when wet preparation for microscopy was adopted (Table 2).

Table 1: Prevalence of Trichomoniasis.

\begin{tabular}{llll}
\hline Sex & $\begin{array}{l}\text { No } \\
\text { Examined }\end{array}$ & $\begin{array}{l}\text { No Positive for } \\
\text { T. vaginalis }\end{array}$ & $(\%)$ \\
\hline Women & 280 & 35 & 12.5 \\
\hline Men & 224 & 13 & 5.8 \\
\hline Total & 504 & 48 & 9.5 \\
\hline
\end{tabular}

Table 2: Analysis of diagnosis of Trichomoniasis in Specimens.

\begin{tabular}{lccccc}
\hline Specimens & No & $\begin{array}{l}\text { Wet } \\
\text { Mount }\end{array}$ & (\%) & Culture & (\%) \\
\hline $\begin{array}{l}\text { High } \\
\text { vaginal } \\
\text { swab }\end{array}$ & 280 & 17 & 6 & 35 & 12.5 \\
\hline $\begin{array}{l}\text { Urethral } \\
\text { swab }\end{array}$ & 224 & 5 & 2 & 13 & 5.8 \\
\hline Urine & 504 & 8 & 1.5 & 18 & 3.5 \\
\hline
\end{tabular}

Table 3a:

Age Distribution of Women with Trichomoniasis.

\begin{tabular}{lccc}
$\begin{array}{l}\text { Age } \\
\text { (Years) }\end{array}$ & $\begin{array}{l}\text { No } \\
\text { Examined }\end{array}$ & $\begin{array}{l}\text { No Positive } \\
\text { for } T . \\
\text { vaginalis }\end{array}$ & $\begin{array}{l}\text { Percentage } \\
\text { (\%) positive of } \\
\text { in positive } \\
\text { women }\end{array}$ \\
\hline $0-10$ & 0 & 0 & 0 \\
$11-20$ & 90 & 16 & 46 \\
$21-30$ & 111 & 11 & 31 \\
$31-40$ & 62 & 8 & 23 \\
$41-50$ & 17 & 0 & 0 \\
$51-60$ & 0 & 0 & 0 \\
$61-70$ & 0 & 0 & 0 \\
\hline
\end{tabular}


Table 3b.

Age Distribution of Men with Trichomoniasis.

\begin{tabular}{llll}
\hline $\begin{array}{l}\text { Age } \\
\text { (Years) }\end{array}$ & $\begin{array}{l}\text { No } \\
\text { Examined }\end{array}$ & $\begin{array}{l}\text { No } \\
\text { positive } \\
\text { for T. T. } \\
\text { vaginalis }\end{array}$ & $\begin{array}{l}\text { Percentage } \\
\text { \%) }\end{array}$ \\
\hline $0-10$ & 0 & 0 & 0 \\
$11-20$ & 45 & 4 & 33 \\
$21-30$ & 107 & 7 & 50 \\
$31-40$ & 56 & 2 & 17 \\
$41-50$ & 16 & 0 & 0 \\
$51-60$ & 0 & 0 & 0 \\
$61-70$ & 0 & 0 & 0 \\
\hline
\end{tabular}

Closer examination at the frequency of isolation of $T$. vaginalis in different age groups irrespective of gender showed that the prevalence of $T$. vaginalis infection was highest in the age group between 21 and 30 (tables $3 \mathrm{a}$ and $3 \mathrm{~b}$ ), followed by the age group between 11 and 20. A low incidence of $17 \%$ was recorded within the age group between 31 and 40 and no positive cases were reported within the age group between 41 and 50 .

The clinical manifestation of $T$. vaginalis infection revealed that 33 patients (68.4\%) complained of vaginal discharge in women and urethral discharge in men (table 4). This was followed by difficulty in passing urine in 20 (42.1\%) out of 53 patients that had trichomoniasis (Table 4) while only 5 patients (10.5\%) complained of irritation in passing urine and increased frequency, respectively.

\section{DISCUSSION}

The prevalence of trichomonad infection was found to be surprisingly low considering the fact that the population examined were those one visited a special treatment clinic - a clinic that is known for treatment of sexually transmitted infections like gonorrhoea, syphilis, and candidiasis. In this study, 48 (9.5\%) of the 504 patients (male and female) were found to have $T$. vaginalis using the most sensitive technique for detection of the organism. A similar study carried out among couples attending fertility clinic in Sagamu (a city that is about 60 miles away from Ibadan) found the prevalence of $T$. vaginalis infection to be $37.9 \%$ (Sule-Odu et al., 2005). Despite the fact that improved method of diagnosis of trichomonad infection was adopted in our study, the prevalence of $T$. vaginalis infection was lower in patients attending special treatment clinic compared to fertility clinic. There is only one plausible explanation for this wide discrepancy in the prevalence of trichomonads in these two communities and this could be due to self administration of antibiotics by patients that had urethritis/vaginitis as a result of pharmacy visit. The consequence of this was under representation of patients infected with $T$. vaginalis. It should also be noted that Ibadan city is more urban in nature compare to Sagamu - a situation that promotes accessibility to pharmacy stores where the individuals could treat themselves. Although, none of these patients admitted to use of any antimicrobial agents prior to reporting to the hospital suggesting that the patients seen at the STC were those that did not treat themselves with antibiotics or not responding to a particular antibiotic or using the wrong antibiotic(s) for the treatment of the infection, hence the visit to the clinic.

Table 4

Clinical Manifestation

\begin{tabular}{lcccc}
\hline Symptoms & Positive & $\%$ & Negative & $\%$ \\
\hline Vaginal/urethra discharge & 33 & 68.7 & 15 & 31.3 \\
\hline Pain on passing urine & 20 & 41.7 & 28 & 58.3 \\
\hline Irritation on passing urine & 5 & 10.4 & 43 & 89.6 \\
\hline Increased frequency & 5 & 10.4 & 43 & 89.6 \\
\hline
\end{tabular}


Having said this, recent study carried out in USA among the young adults showed the prevalence of trichomoniasis to be $2.3 \%$ of the 18,924 participants (Miller et al., 2005), suggesting the prevalence of trichomoniasis in the general community would be much lower than actually looking at individual clinical setting.

Age distribution of patients having trichomonaisis shows similarity to that of other sexually transmitted infections such as gonorrhoea and chlamydia (Bakare et al., 2002, Kehinde and Lawoyin, 2005). Trichomoniasis was found to be more prevalent in $79 \%$ of women and $68 \%$ of men infected with $T$. vaginalis respectively, with age bracket of 11 to 30 years among the infected individuals in this study than other age groups. This does not come to us as a surprise as this is the period of highest level of sexual activity and those in this age group tend to be more promiscuous than other age groups and therefore prone to STI. Trichomoniasis is uncommon among children and virgins, but most common between the ages of 16 and 35 years, which is usually the period of greater sexual activity. If this association holds true, the large percentage of single women and men investigated (53\% and 26\% respectively, $79 \%$ in all) should not be unexpected. Majority of patients attend STC of the University College Hospital, Ibadan because of various complaints such as vaginal/urethral discharge, pain in passing urine. Sixty eight percent of patients infected with trichomoniasis had discharge (vaginal and urethral), 42.1\% had pain in passing urine while $10.5 \%$ had increased frequency. This is similar to the findings of Dunlop and Wisdom (1965) in which 64\% complained of discharge, $24 \%$ pain in passing urine and $52 \%$ had irritation in passing urine (Dunlop, 1965).

Many workers have found cultural methods to be superior to other methods such as fresh wet mount examinations and staining of smears. This has been confirmed by this study. While only $42.1 \%$ of patients with $T$. vaginalis were diagnosed by direct wet mount preparation, all the 48 (100\%) positive cases were diagnosed by cultural methods irrespective of the medium used. Recently, Radonjic et al (2005) compared three methods of diagnosis of $T$. vaginalis infection and found that cultural method was able to detect $10.5 \%$ of trichomonad in the population studied compared to $7 \%$ using wet mount preparation for microscopy (Radonjic et al., 2005). In the same study, PCR was able to detect T. vaginalis in $11 \%$ of the population investigated.

Trichomoniasis can be associated with some complications such as acute epididymitis and $T$. vaginalis has been isolated from epididymal aspirates (Krieger, 1981) This has been confirmed in this environment (Ogunbanjo et al., 1989), who by retrospective study reported infective factors of male sterility among Nigerians in which $T$. vaginalis was found to be one of the causative agents of conjugal sterility. Furthermore, it is not only that $T$. vaginalis can be found associated with other STIs, this organism has been shown to increase the transmission of HIV, which may be brought about by genital ulceration as a result of several enzymes secreted by $T$. vaginalis (Draper et al., 1998, Sorvillo et al., 2001). The recent linking of T. vaginalis infection with cervical cancer (Sayed el-Ahl et al., 2002), if confirmed by other investigators, shows that a better surveillance for this organism has to be put in place in order to reduce the cases of cervical cancer and HIV. It is a normal practise in medical microbiology laboratory in Africa to use only wet preparation/stained smear in diagnosis of $T$. vaginalis. This practise needs to be discouraged because of the implication of misdiagnosis of infection. The integration of cultural method of diagnosis will be a way forward in screening both asymptomatic and symptomatic populace.

\section{REFERENCES}

Adebayo, J. A. (1986): Med Lab Sci, 43, 91-2.

Bakare, R. A., Oni, A. A., Umar, U. S., Okesola, A. O., Kehinde, A. O., Fayemiwo, S. A. and Fasina, N. A. (2002): Afr J Med Med Sci, 31, 17-20.

Buve, A., Weiss, H. A., Laga, M., Van Dyck, E., Musonda, R., Zekeng, L., Kahindo, M., Anagonou, S., Morison, L., Robinson, N. J. and Hayes, R. J. (2001): Aids, 15 Suppl 4, S89-96.

Cates, W., Jr. (1999): Sex Transm Dis, 26, S2-7. 
Cotch, M. F., Pastorek, J. G., 2nd, Nugent, R. P., Hillier, S. L., Gibbs, R. S., Martin, D. H., Eschenbach, D. A., Edelman, R., Carey, J. C., Regan, J. A., Krohn, M. A., Klebanoff, M. A., Rao, A. V. and Rhoads, G. G. (1997): Sex Transm Dis, 24, 353-60.

Draper, D., Donohoe, W., Mortimer, L. and Heine, R. P. (1998): J Infect Dis, 178, 815-9.

Dunlop, E. M. C. a. W., A.R. (1965): British Journal of Venereal Diseases, 41, 85.

Hardy, P. H., Hardy, J. B., Nell, E. E., Graham, D. A., Spence, M. R. and Rosenbaum, R. C. (1984): Lancet, 2, 333-7.

Hienstra, I., F. Van Belm, and H.M. Bergerm (1984): British Medical Journal, 289, 355-356.

Hobbs, M. M., Kazembe, P., Reed, A. W., Miller, W. C., Nkata, E., Zimba, D., Daly, C. C., Chakraborty, H., Cohen, M. S. and Hoffman, I. (1999): Sex Transm Dis, 26, 381-7.

Kampmeier, R. H. (1978): Sex Transm Dis, 5, 119. Kehinde, A. O. and Lawoyin, T. O. (2005) Afr J Reprod Health, 9, 42-8.

Klouman, E., Masenga, E. J., Klepp, K. I., Sam, N. E., Nkya, W. and Nkya, C. (1997): J Acquir Immune Defic Syndr Hum Retrovirol, 14, 163-8.

Krieger, J. N. (1981): Invest Urol, 18, 411-7.

Krieger, J. N., Verdon, M., Siegel, N. and Holmes, K. K. (1993): J Urol, 149, 1455-8.

Laga, M., Manoka, A., Kivuvu, M., Malele, B.,
Tuliza, M., Nzila, N., Goeman, J., Behets, F., Batter, V., Alary, M. and et al. (1993): Aids, 7, 95102.

Leroy, V., De Clercq, A., Ladner, J., Bogaerts, J., Van de Perre, P. and Dabis, F. (1995): Genitourin Med, 71, 207-11.

Meri, T., Jokiranta, T. S., Suhonen, L. and Meri, S. (2000): J Clin Microbiol, 38, 763-7.

Miller, W. C., Swygard, H., Hobbs, M. M., Ford, C. A., Handcock, M. S., Morris, M., Schmitz, J. L., Cohen, M. S., Harris, K. M. and Udry, J. R. (2005): Sex Transm Dis, 32, 593-8.

Ogunbanjo, B. O., Osoba, A. O. and Ochei, J. (1989): Afr J Med Med Sci, 18, 35-8.

Radonjic, I. V., Dzamic, A. M., Mitrovic, S. M., Arsic Arsenijevic, V. S., Popadic, D. M. and Kranjcic Zec, I. F. (2005): Eur J Obstet Gynecol Reprod Biol.

Sayed el-Ahl, S. A., el-Wakil, H. S., Kamel, N. M. and Mahmoud, M. S. (2002): J Egypt Soc Parasitol, 32, 167-78.

Sorvillo, F., Smith, L., Kerndt, P. and Ash, L. (2001): Emerg Infect Dis, 7, 927-32.

Sule-Odu, A. O., Oladapo, O. T., Jagun, O. E. and Awosile, J. (2005): J Obstet Gynaecol, 25, 685-8. 